\title{
Myeloma Patient Value Mapping: A Discrete Choice Experiment on Myeloma Treatment Preferences in the UK
}

This article was published in the following Dove Press journal: Patient Preference and Adherence

\author{
Simon Fifer ${ }^{1}$ \\ Jayne Galinsky ${ }^{2}$ \\ Sarah Richard ${ }^{3}$ \\ 'Community and Patient Preference \\ Research (CaPPRe), Sydney, NSW, \\ Australia; ${ }^{2}$ Myeloma UK, Edinburgh, \\ Scotland; ${ }^{3}$ PRMA, Edinburgh, Scotland
}

Correspondence: Simon Fifer

Community and Patient Preference

Research (CaPPRe), Sydney, NSW,

Australia

Tel +6I 403862091

Email simon.fifer@cappre.com.au
Background: Myeloma is an incurable life-threatening hematological cancer. Recent treatment developments have seen improvements in survival; however, while patients are living longer, they are living with symptoms and treatment side effects.

Objective: To evaluate myeloma patients' preferences for treatment using a discrete choice experiment (DCE). This study set out to define the relative importance of key treatment attributes, characterize the risk-benefit trade-offs in patients' decision-making, and to analyze the predictive power of basic demographic factors.

Methods: Four hundred seventy-five myeloma patients in the UK were invited to participate by Myeloma UK. Data were collected using DCEs through an online survey. The DCEs presented patients with 10 choice scenarios, each with 2 treatment options described by 7 attributes, and a "no treatment" option. The DCE data were modelled using a latent class model (LCM). The effects of demographic characteristics were also examined.

Results: Not surprisingly, average survival was most important to all patients but there were significant contrasts between the class preferences. The LCM revealed two classes of patients. Patients in Class 1 placed greater importance on average survival and mild-tomoderate side effects, whereas patients in Class 2 focused on the mode of administration and the average out-of-pocket costs. Patients living with others and those diagnosed in the last 5 years were more likely to be in Class 1 .

Conclusion: Different treatment features were not valued equally among all myeloma patients. This has important implications for healthcare policy decisions and could be used to guide decisions around the value of new myeloma medicines.

Keywords: discrete choice experiment, patient preferences, myeloma, health technology assessment, dashboards

\section{Introduction}

Myeloma is a disorder of the plasma cells characterized by the proliferation of malignant plasma cells in the bone marrow. ${ }^{1}$ It is the 17 th most common cancer in the UK, accounting for $2 \%$ of all new cases. ${ }^{2}$ Although myeloma is sensitive to treatments, there remains no cure. Recent years have seen improvements in survival as a result of routine use of high-dose therapy, autologous stem cell transplant and the introduction of novel therapies, ${ }^{3}$ and today, a third (33\%) of people diagnosed with myeloma in England and Wales will survive myeloma for 10 years or more. ${ }^{2}$

These improvements see a paradigm shift towards treating myeloma as a chronic condition, with patients more likely to be exposed to multiple combinations of treatments, 
as well as longer periods of treatment use. Whilst current treatments aim to increase overall survival, prolong remission and improve quality of life for myeloma patients, they also incur variable risks of negative physiological effects, as well as potential financial and practical burdens on patients. Research additionally suggests that myeloma patients have a higher burden of disease than many other cancers. ${ }^{4}$ Therefore, myeloma patients are often confronted with a complex trade-off between benefits and risks, and favourable and unfavourable treatment attributes, particularly when including the option of no treatment.

Patient preferences is a common term used to describe the data elicited by methods that capture patients' preferences for hypothetical or actual treatment attributes. Such data is increasingly recognised as having a key role to play in research and development decision-making, and in regulatory and health resource allocation contexts.

Evidence for myeloma patient preferences is critical for informing the future development and prioritisation of new treatments and helping position myeloma treatments in the care pathway. It is also important in assisting regulators and health technology assessment agencies to understand the acceptability and value proposition of new treatments, especially since literature suggests that healthcare professionals (HCPs) are often unaware of individual patient's preferences for treatment in myeloma, ${ }^{5}$ and in some cases, have considerably underestimated patient pain or quality of life. .,7 $^{6}$

The aim of this study was to elicit myeloma patients' preferences on hypothetical treatment attributes that are common to a broad range of myeloma treatments in current use. The study set out to define the relative importance of a set of key treatment attributes to myeloma patients, to characterize the risk-benefit trade-offs in patients' decision-making, and to analyze whether individual factors (eg, patient demographics or prior treatment history) can be used as a predictor of patient preferences for treatment.

\section{Methods}

\section{Survey Design}

A sample of 475 Myeloma patients in the UK completed the study in September 2016. Patients were invited to participate by Myeloma UK using email, social media, and support groups. Participants provided informed consent prior to participating in the study. Patients were selected using rigorous criteria. To qualify, they were required to self-report having been formally diagnosed with MM. The survey included approximately 12 questions to identify MM patients including their diagnosis, duration of diagnosis, treatment situation, treatment details, side effects and open-ended questions about quality of life and caregivers and to screen out fraudulent responses, if any. The sample size is consistent with the minimum sample size requirements proposed in BekkerGrob et al for DCEs in healthcare. ${ }^{8}$

Data were collected through an online survey. The survey instrument included 5 sections; i) socio-demographic information; ii) treatment background; iii) quality of life; iv) treatment preferences/DCE and v) survey feedback. The survey started with a participant information page which included background details to the survey including the purpose of the study, organizations involved, average completion time and information on privacy and confidentiality. The online survey was pilot tested prior to launching to test for validity and reliability.

We used Confirmit, a secure online research platform for data collection. All participants were informed at the beginning of the survey that information collected will be treated confidentially and responses will be anonymised when presenting the results. Confidentiality and anonymity of respondents were protected throughout. Respondent IP addresses were not collected. The survey was entirely voluntary, and no incentive was given for participants who completed the survey. As the survey included questions of sensitive nature, participants were given the possibility to withdraw their participation anytime during the survey.

The cross-sectional data were analyzed using state of the art discrete choice experiments (DCE). ${ }^{9,10}$ Additional demographic questions were also included in the survey to examine the influence of demographic characteristics on treatment preferences. Patient demographics are displayed in Table 1. Data from 56 patients were removed during data cleaning because they indicated they had a difficulty in understanding the survey. The patients were roughly evenly split by gender and skewed towards the older age group, which is common for MM. Overall, most patients who completed the survey were currently receiving treatment for MM (32.7\%) or in remission following treatment (45.1\%) (Table 1).

DCEs have a long and established research history in modelling decision-making, based on formative research in Psychology and Economics. ${ }^{11-14}$ This research was expanded in the 1980s through experimental design. ${ }^{15,16}$ DCEs are comprised of choice scenarios where decision-makers are required to select their preferred option from a set of competing alternatives (which collectively form a choice scenario). Showing multiple choice scenarios, over which the features of the 
Table I Patient Demographics

\begin{tabular}{|c|c|c|}
\hline \multicolumn{2}{|l|}{ Characteristics } & \multirow{2}{*}{$\begin{array}{l}\text { Patients (N=419) } \\
233(55.61) \\
186(44.39)\end{array}$} \\
\hline Gender N (\%) & $\begin{array}{l}\text { Female } \\
\text { Male }\end{array}$ & \\
\hline Age N (\%) & $\begin{array}{l}3 I-40 \\
4 I-50 \\
5 I-60 \\
6 I-70 \\
7 I-80 \\
8 I \text { or older }\end{array}$ & $\begin{array}{l}3(0.72) \\
27(6.44) \\
93(22.2) \\
201(47.97) \\
87(20.76) \\
8(1.91)\end{array}$ \\
\hline Ethnic group N (\%) & $\begin{array}{l}\text { White British } \\
\text { Asian or Asian British } \\
\text { Black or Black British } \\
\text { Mixed ethnicity } \\
\text { Other, please specify } \\
\text { Prefer not to answer }\end{array}$ & $\begin{array}{l}401(95.7) \\
2(0.48) \\
1(0.24) \\
2(0.48) \\
12(2.86) \\
1(0.24)\end{array}$ \\
\hline Occupation status N (\%) & $\begin{array}{l}\text { Working (full-time or part-time) } \\
\text { Not working } \\
\text { Retired } \\
\text { Other, please specify }\end{array}$ & $\begin{array}{l}72(17.18) \\
37(8.83) \\
289(68.97) \\
21(5.01)\end{array}$ \\
\hline Household type N (\%) & $\begin{array}{l}\text { Living alone } \\
\text { Living with others }\end{array}$ & $\begin{array}{l}61(14.56) \\
358(85.44)\end{array}$ \\
\hline Cares for dependent family members $\mathrm{N}$ (\%) & $\begin{array}{l}\text { Yes } \\
\text { No } \\
\text { Prefer not to answer }\end{array}$ & $\begin{array}{l}60(14.32) \\
357(85.2) \\
2(0.48)\end{array}$ \\
\hline Key people supporting their Myeloma $N(\%)$ & $\begin{array}{l}\text { Spouse/partner } \\
\text { Other relative } \\
\text { Friend } \\
\text { NHS professional } \\
\text { Other }\end{array}$ & $\begin{array}{l}339(80.91) \\
86(20.53) \\
48(11.46) \\
106(25.3) \\
25(5.97)\end{array}$ \\
\hline Current treatment $\mathrm{N}(\%)$ & $\begin{array}{l}\text { Diagnosed with myeloma but not requiring treatment } \\
\text { Require first treatment but have not yet started } \\
\text { Require second or subsequent treatment but not yet started } \\
\text { In remission following treatment } \\
\text { Receiving treatment } \\
\text { Other } \\
\text { Not sure }\end{array}$ & $\begin{array}{l}19(4.53) \\
1(0.24) \\
24(5.73) \\
189(45.11) \\
137(32.7) \\
47(11.22) \\
2(0.48)\end{array}$ \\
\hline
\end{tabular}

Abbreviations: $\mathrm{N}$, indicates frequency; \%, percentage of responses.

alternatives are systematically varied, allows for a determination of how each of the features impact upon the preferences of a sampled population. DCEs have been used routinely in other disciplines, such as transport and marketing since the $1980 \mathrm{~s}^{17}$ and have become more frequently used in health to understand stakeholder preferences in the last decade. ${ }^{18}$

\section{Selection of Attributes}

The attributes shown in the DCE scenario were selected based on literature reviews, pilot interviews with patients facilitated by Myeloma UK (approximately 5 patients), secondary research (clinical trial data) and expert opinion (including physicians, 2 physicians were included in the discussions). After reviewing the importance of attributes and levels, the following were included in the DCE: mode and frequency of administration, ${ }^{19}$ annual out-of-pocket costs, average overall survival, ${ }^{20,21}$ remission period ${ }^{22}$ and side effects. ${ }^{20,21,23}$ In addition to the chosen attributes, further therapies ${ }^{24}$ were initially considered but not included in the DCE. The final attributes were selected 
because they matched feedback from patients and mapped directly to current/future treatment characteristics. Attribute and level details are described in Table 2.

The experimental design followed good practice guidelines $^{25}$ and the combinations of levels presented in the tasks were designed using a D-efficient design based on naïve priors accounting for parameter sign in NGene v1.1.2 (ChoiceMetrics). ${ }^{26}$ The final design consisted of 70 scenarios, blocked into 7 versions of 10 questions. Mode/frequency of treatment, average sur$\mathrm{vival} / \mathrm{remission}$ period and risk/duration of side effects were nested in the design because the attributes and levels were linked.

The DCE presented patients with a traditional treatment choice experiment focusing on the clinical benefits of treatments and the associated risks. Each participant was presented

Table 2 Attribute Levels

\begin{tabular}{|c|c|c|}
\hline $\begin{array}{l}\text { Attribute } \\
\text { Mode/Frequency of administration }\end{array}$ & \multicolumn{2}{|l|}{ Description } \\
\hline & Oral & $\begin{array}{l}\text { Daily } \\
2-3 \text { times per week } \\
\text { Weekly }\end{array}$ \\
\hline & Subcutaneous & $\begin{array}{l}2-3 \text { times per week } \\
\text { Weekly } \\
\text { Fortnightly } \\
\text { Monthly }\end{array}$ \\
\hline & Intravenous & $\begin{array}{l}\text { Weekly } \\
\text { Fortnightly } \\
\text { Monthly }\end{array}$ \\
\hline Annual out-of-pocket costs (pounds) & & $\begin{array}{l}0 \\
400 \\
800 \\
1200 \\
1600\end{array}$ \\
\hline \multirow[t]{5}{*}{ Average overall survival/Remission period } & I year & $\begin{array}{l}3 \text { months } \\
9 \text { months }\end{array}$ \\
\hline & 2 years & $\begin{array}{l}6 \text { months } \\
1 \text { year } 6 \text { months }\end{array}$ \\
\hline & 3 years & $\begin{array}{l}9 \text { months } \\
2 \text { years } 3 \text { months }\end{array}$ \\
\hline & 4 years & $\begin{array}{l}\text { I year } \\
3 \text { years }\end{array}$ \\
\hline & 5 years & $\begin{array}{l}1 \text { year } 3 \text { months } \\
3 \text { years } 9 \text { months }\end{array}$ \\
\hline Mild-to-moderate side effects & & $\begin{array}{l}\text { None } \\
\text { Low risk (20\%) - Duration (up to } 2 \text { months) } \\
\text { Low risk ( } 20 \% \text { - Duration (longer than } 2 \text { months) } \\
\text { Med risk ( } 40 \%) \text { - Duration (up to } 2 \text { months) } \\
\text { Med risk ( } 40 \%) \text { - Duration (longer than } 2 \text { months) } \\
\text { High risk }(60 \%) \text { - Duration (up to } 2 \text { months) } \\
\text { High risk }(60 \%) \text { - Duration (longer than } 2 \text { months) }\end{array}$ \\
\hline Severe side effects & & $\begin{array}{l}\text { None } \\
\text { Low risk (5\%) - Duration (up to } 2 \text { months) } \\
\text { Low risk (5\%) - Duration (longer than } 2 \text { months) } \\
\text { High risk ( } 10 \% \text { - Duration (up to } 2 \text { months) } \\
\text { High risk ( } 10 \% \text { - Duration (longer than } 2 \text { months) }\end{array}$ \\
\hline
\end{tabular}


with 10 choice scenarios where participants were asked to choose between three alternatives. These consisted of two hypothetical treatment options $\mathrm{A}$ and $\mathrm{B}$ and a "Neither of these" option. The neither treatment option indicates respondents have no preference for Treatment A or Treatment B and would continue to explore current options. Patients were asked to imagine that their doctor had advised that they needed to receive treatment and they had a choice between the presented options. An example scenario is displayed in Figure 1. Words and images were used in the scenarios to make them easier for patients to decode information and make choices.

\section{Statistical Analysis}

DCEs are based on Random Utility Theory (RUT). ${ }^{11,12}$ RUT assumes that the total utility of a product (eg, treatment) can be expressed as a systematic component, expressed as a function of the attributes presented and a random or unexplained component. Further, it is assumed that the decision-makers compare the alternatives within a scenario and selects the option that yields the maximum utility (ie, the respondent is a utility maximiser).

The simplest discrete choice model is called the Multinomial Logit model (MNL). The MNL has certain restrictive assumptions which restrict its use in practice. More advanced models, including the Mixed Multinomial Logit (MMNL) and latent class model (LCM), allow for the relaxation of some or all of these restrictive assumptions. ${ }^{27}$ The modelling of the data for this study will focus on the latent class model $(\mathrm{LCM}) .^{28}$ Statistical analyses were performed in NLOGIT version 6 (Econometric Software, Inc.). ${ }^{29}$

The LCM allows for preference heterogeneity such that different patients can have different marginal utility or parameter weights for each of the features. This is handled via discrete distribution. These discrete distributions are referred to as "classes". According to the model, each individual resides up to a probability in each "latent" class, $c$. In estimating the model, there exists a fixed number of classes, $C$, defined a priori by

\begin{tabular}{|c|c|c|c|}
\hline Factors & Treatment A & Treatment B & $\begin{array}{l}\text { Neither of these } \\
\text { treatments }\end{array}$ \\
\hline $\begin{array}{c}\text { Average overall } \\
\text { survival }\end{array}$ & 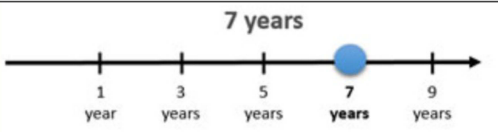 & 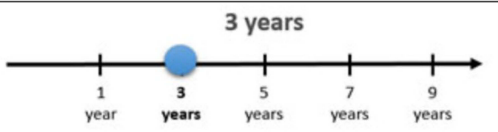 & \\
\hline $\begin{array}{c}\text { Average remission } \\
\text { period }\end{array}$ & 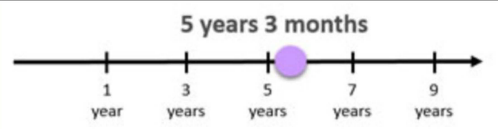 & 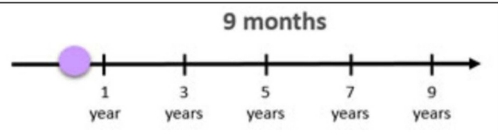 & \\
\hline$\frac{\text { Mild or Moderate }}{\text { side-effects }}$ & 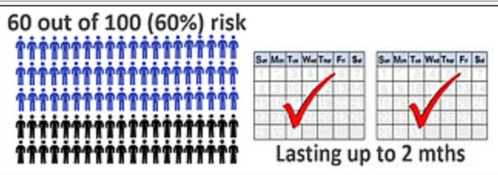 & 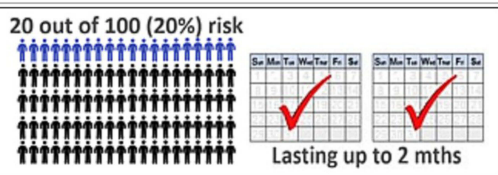 & \\
\hline $\begin{array}{l}\text { Severe } \\
\text { side-effects }\end{array}$ & 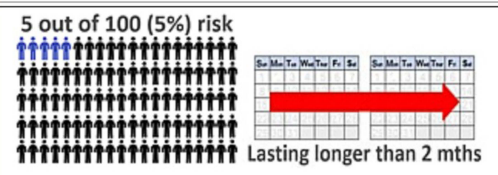 & 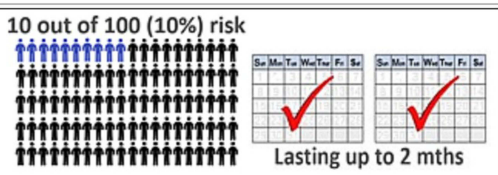 & \\
\hline $\begin{array}{c}\text { How treatment is } \\
\text { taken }\end{array}$ & $\begin{array}{l}\text { Intravenous drip } \\
\text { (Hospital / clinic) } \\
\text { Time: } 2-3 \text { hours }\end{array}$ & $\begin{array}{l}\text { Subcutaneous Injection } \\
\text { (Hospital / clinic) } \\
\text { Time: } 15 \text { mins }\end{array}$ & \\
\hline $\begin{array}{c}\text { Frequency of taking } \\
\text { treatment }\end{array}$ & 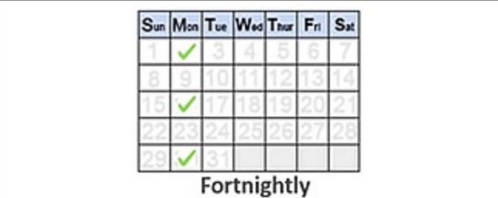 & 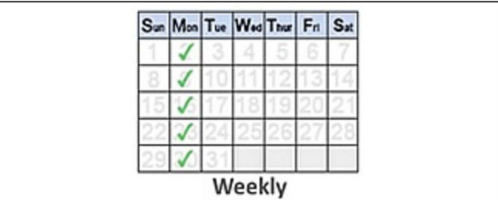 & \\
\hline $\begin{array}{l}\text { Average out of pocket } \\
\text { costs to you } \\
\text { over a year }\end{array}$ & $£ 0$ & $£ 0$ & \\
\hline I would choose & Treatment A & Treatment B & Neither \\
\hline
\end{tabular}

Figure I Example of a DCE scenario. 
the analyst. The estimates consist of the class-specific parameters, and a set of probabilities defined over the classes for each individual. Within each class, the parameters and choice probabilities are assumed to be generated by Multinomial Logit (MNL) models. LCM has become more frequently used in health over the last decade. ${ }^{30}$ Additionally, the LCM can account for the effect of patient characteristics on their treatment preferences. $^{28,31}$

\section{Results}

\section{Model}

The median time for survey completion was 18 mins. Data from 56 patients were removed during data cleaning because they indicated they had a difficulty in understanding the survey. The difficulty in understanding the DCE scenarios was tested with a question that allowed respondents to rate their understanding on a scale of 1 to 10 . The appropriate number of classes was evaluated by estimating models with different numbers of classes and comparing parameters estimates and using Akaike Information Criterion (AIC) and Bayesian information criterion (BIC). The final LCM selected specified two groups of patients (or classes). The model results are displayed in Table 3. All parameters were treated as categorical and dummy coded. A constant was estimated for the opt-out (Neither) alternative relative to the hypothetical treatment alternatives. Duration of side effects was not significant, and hence nested levels were collapsed for estimation. Nested levels for mode/frequency were regrouped to facilitate modelling and interpretation. An interaction term between average survival and remission period was estimated but was removed because it was insignificant. Therefore, average survival and remission period were estimated separately.

\section{Attribute Importance}

Attribute importance can be calculated in a number of ways depending on the model structure. In standard choice models, the parameters cannot be typically directly compared as the attributes represented by each parameter are presented on different scales. In this case, because the attributes were categorically dummy coded, we can compare the change in utility from the lowest level to the highest level for each parameter. Doing so for each attribute provides a measure of relative importance. ${ }^{32}$ Figure 2 presents the relative importance of each attribute (average survival, remission period, treatment mode/frequency, yearly out-of-pocket costs, mild side effects, and severe side effects), by class for the average model (no class assignment). Average survival, severe side effects and treatment mode/frequency were considered the most important attributes to patients overall. It should be noted that relative importance is dependent on the attribute levels chosen for the experiment and should be viewed in this context.

\section{Classes (Patient Segments)}

Observing the relative attribute importance of the treatment attributes shown visually in Figure 2 can reveal the differences between these classes. Average survival was considered the most important attribute across both classes. However, there were large differences in the relative preference for average survival and preferences for other attributes between the classes. Class 1 placed more importance on average survival and the risk of experiencing mild-to-moderate side effects (compared to Class 2), whereas those in Class 2 were more heavily focused on how the treatment is administered and the yearly average out-of-pocket cost (compared to Class 1).

\section{Class Membership}

The LCM allows the addition of patient characteristics to test whether they influence the probability of a patient belonging to a particular class. The following patient characteristics were tested to see if they were linked to class membership; gender, age, living with dependents, living alone, recently diagnosed, currently in remission, currently on treatment, experienced severe side effects. Patients living alone, patients diagnosed recently (in the last 5 years) and patients who had experienced severe side effects were significant predictors of class membership. Patients living with others (ie, not living alone) and those diagnosed in the last 5 years were more likely to be in Class 1 compared to Class 2. It is intuitive that patients living with others were more likely to be in class 1 where they placed more importance on average survival. Likewise, patients who have been on treatment for longer (ie, not diagnosed recently) were more likely to be in class 2 where they placed more importance on the mode/frequency of treatment. Linking patient characteristics to class membership in this way allows researchers to build a story around the observed class preference differences.

\section{Visualisation of Model Results - Dashboard}

The results have been integrated into a dashboard, which enables stakeholders to perform scenario analysis. ${ }^{33}$ This includes allowing the user to input the 
Table 3 Model Parameters

\begin{tabular}{|c|c|c|c|c|}
\hline & \multicolumn{2}{|l|}{ Class I } & \multicolumn{2}{|l|}{ Class 2} \\
\hline \multirow{2}{*}{$\begin{array}{l}\text { Class Proportions } \\
\text { Utility Parameters }\end{array}$} & \multicolumn{2}{|l|}{0.635} & \multicolumn{2}{|l|}{0.365} \\
\hline & Parameter & T-Ratio & Parameter & T-Ratio \\
\hline \multicolumn{5}{|c|}{ (Reference category: Oral - Low frequency 2-3 times/weekly) } \\
\hline Oral - High Frequency (Daily) & 1.149 & 2.36 & 0.130 & 0.73 \\
\hline Intravenous - Low Frequency (Fortnightly/Monthly) & 0.473 & 1.04 & -0.401 & -2.75 \\
\hline Intravenous - High Frequency (2-3 times/weekly) & -0.235 & -0.88 & -0.907 & -4.99 \\
\hline Subcutaneous - Low Frequency (Fortnightly/Monthly) & 0.622 & 1.57 & -0.166 & -1.11 \\
\hline Subcutaneous - High Frequency (2-3 times/weekly) & -0.439 & -1.38 & -0.572 & -3.84 \\
\hline \multicolumn{5}{|l|}{ (Reference category: Free $€ 0$ ) } \\
\hline Out-of-pocket cost $-€ 400 / 800$ & -0.028 & -0.11 & -0.263 & -2.12 \\
\hline Out-of-pocket cost $-€ 1200$ & -0.327 & -1.03 & -0.402 & -2.8 \\
\hline Out-of-pocket cost $-€ 1600$ & -0.279 & -0.79 & -0.612 & -4.22 \\
\hline \multicolumn{5}{|l|}{ (Reference category: I year) } \\
\hline Average survival -3 years & 6.101 & 5.93 & 0.672 & 3.89 \\
\hline Average survival -5 years & 9.610 & 8.29 & 1.578 & 9.73 \\
\hline Average survival -7 years & 11.843 & 9.11 & 2.194 & 13.35 \\
\hline Average survival -9 years & 14.034 & 9.74 & 2.619 & $|4.5|$ \\
\hline \multicolumn{5}{|l|}{ (Reference category: Long remission period) } \\
\hline Short remission period & -1.986 & -7.72 & -0.598 & -6.72 \\
\hline \multicolumn{5}{|c|}{ (Reference category: Low to medium risk of mild-to-moderate side effects) } \\
\hline No mild-to-moderate side effects & 0.418 & 1.12 & 0.414 & 2.69 \\
\hline High risk of mild-to-moderate side effects & -0.724 & -4.01 & -0.181 & -1.81 \\
\hline \multicolumn{5}{|l|}{ (Reference category: Low risk of severe side effects) } \\
\hline No severe side effects & 0.555 & 1.84 & 0.545 & 4.23 \\
\hline High risk of severe side effects & -0.438 & -1.82 & -0.155 & -1.61 \\
\hline Neither treatment (constant) & -4.939 & -4.04 & -0.267 & -1.21 \\
\hline \multicolumn{5}{|l|}{$\begin{array}{l}\text { Class membership - Class I } \\
\text { (Reference category: Class 2) }\end{array}$} \\
\hline Constant & 0.699 & 3.46 & & \\
\hline Living alone & -0.874 & -2.59 & & \\
\hline Diagnosed recently & 0.386 & 1.68 & & \\
\hline Experienced severe side effects & -0.479 & -1.97 & & \\
\hline \multicolumn{5}{|l|}{419 participants, Number of choice observations: 4190.} \\
\hline
\end{tabular}

features of a treatment and compare it to another treatment (eg, new treatment entering the market compared to an existing treatment) and see what proportion of patients would prefer each treatment (ie, treatment alignment with patient values). Interacting with the data in this way is one of the best ways to illustrate the results from a DCE to stakeholders. An example screen is shown in Figure 3. The dashboard was built using R Shiny v1.3.1 (RStudio, Inc., Boston, MA, USA) and is displayed as a webpage. ${ }^{34}$

\section{Discussion}

The purpose of the study is to uncover how patients trade-off the benefits and risks/costs of myeloma treatment and to elicit 


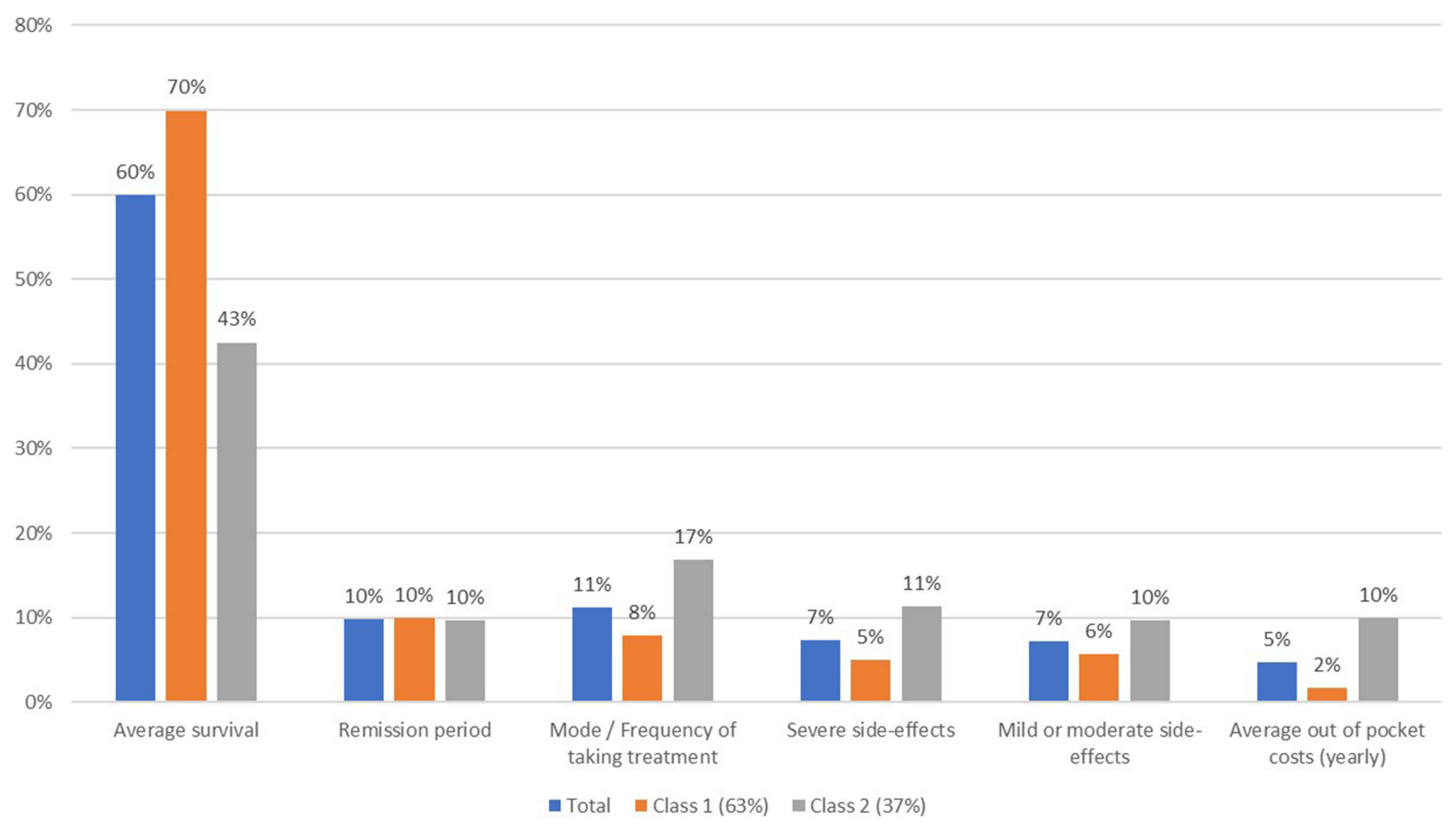

Figure 2 Relative attribute importance.

\section{CaPPRe Myeloma Dashboard Treatnent Préerences}

\begin{tabular}{|c|c|}
\hline $\begin{array}{l}\text { Treatment A } \\
\text { Mode of administration }\end{array}$ & $\begin{array}{l}\text { Treatment B } \\
\text { Mode of administration }\end{array}$ \\
\hline Oral $\quad$ IV & Oral \\
\hline Frequency of taking treatment & Frequency of taking treatment \\
\hline Low & Low \\
\hline $\begin{array}{l}\text { Average survival } \\
\text { tyears }\end{array}$ & Average survival \\
\hline 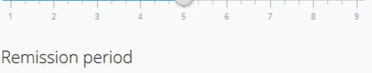 & 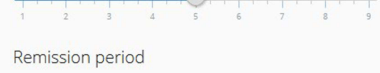 \\
\hline Short (25\%) & Short (25\%) \\
\hline Average out of pocket cost (yearly) & Average out of pocket cost (yearly) \\
\hline $\begin{array}{lllllll}50 & & & & & & \\
\end{array}$ & 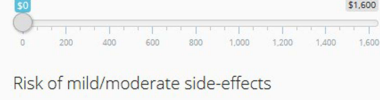 \\
\hline None & None \\
\hline Risk of severe side-effects & Risk of severe side-effects \\
\hline None & None \\
\hline
\end{tabular}

Figure 3 Treatment comparison dashboard.

their preferences on treatment attributes that are common to a broad range of myeloma treatments. It provides an understanding of what patients with myeloma value when evaluating treatments. Findings from this study suggest that different treatment features were not valued equally among all myeloma patients. This is reflective of the literature in other cancers, such as breast cancer ${ }^{35,36}$ where researchers have found that factors such as age and potential frequency of hospital visits influence what patients want from their treatment (for example, when deciding between breast conserving or mastectomy surgeries 
or not). Our findings additionally reflect other patient preference work in myeloma. ${ }^{24,37,38}$ In a recent German study examining patient preferences for relapsed refractory multiple myeloma treatments, they found that mode of administration and progression-free survival were the most important features. ${ }^{37}$ Our results match these findings with remission period and mode/treatment frequency being equally important, second only to overall survival which was not included in the German study. Postmus et al's (2017) recent study examined trade-offs between possible benefits and risks of treatments in myeloma. ${ }^{38}$ These researchers found that participants who ranked severe or life-threatening toxicity above mild or moderate toxicity were more frequently younger, working, and looking after dependent family members. Findings echo this current preference study, where a divide existed between patients who placed more importance on survival and mildto-moderate side effects and patients who placed more importance on the mode and frequency of treatment. Both studies demonstrate that there is variance around what characteristics of treatment patients with myeloma value in the UK.

\section{Application of Findings}

Findings from our study, and the wider literature, highlight the importance of understanding key patient characteristics when inferring likely patient preferences for treatments. At an individual level, this has implications for the myeloma clinic and joint discussions with patients and HCPs. Information about treatment-related factors such as side effects and extra hospital visits should play a large role in shared decision-making discussions about medicines, with HCPs having an awareness that differing individuals and groups may be willing to accept more or less side effects, more or less risk, and greater or lesser costs of a medicine.

At a population level, our findings have implications for health technology assessment processes. Muhlbacher and Johnson (2017) write that regulators are under pressure to ensure that their decisions are aligned with patient needs. ${ }^{5}$ Patient elicitation studies such as this respond to such pressures by providing HTA bodies with robust patient (and potentially other stakeholder too) data so that experts can integrate and implement these preferences into their decision-making processes.

Dashboards generated from this study will also be used to influence thinking during the planning and development stages of future Myeloma UK trials in the UK. The interactive nature of the dashboards will enable clinical trials professionals to understand the characteristics of different patient groups, integrating methods of personalisation and stratification. Methodologies like this, if used early enough in the drug development process, have the potential to highlight patients' acceptance and perception of new medicines in advance of PPI review processes already integrated into the Myeloma UK Clinical Trials Network. The use of such elicitation methodologies therefore has the potential to prevent upfront and high costs around developing new treatments, for such treatments to be later deemed to have too many risks or disadvantages for it to be acceptable to patients and brought to market.

\section{Future Research}

This study shows that discrete choice experiments can feasibly generate an understanding of what patients with myeloma would be willing to accept from medicine. However, in the future, it would be useful to gain a greater understanding of what carers, HCPs, and payers understand and think about the acceptability and value proposition of new treatments and compare this to the findings from patients presented and discussed in this paper. It would also be useful to conduct future longitudinal preference studies to understand further how patient preferences change over time and throughout the myeloma trajectory.

\section{Limitations of the Study}

Unfortunately, due to study limitations, the survey was only offered online. This may induce a bias if there is a relationship between patient characteristics and the use of online technology. Further, it should be noted that the sample was sourced solely through Myeloma UK channels. Patients who are involved with advocacy groups may be more informed and involved in their condition than other Myeloma patients in the UK. It would be worth exploring in future research whether recruitment methods and survey completion modes significantly impact the findings.

\section{Conclusion}

Findings from this study add to the growing literature ${ }^{39,40}$ on the importance of quality of life to patients with myeloma. The study also highlights how preference elicitation methods such as DCEs can be used to understand what is important to patients when evaluating treatments. Interestingly, not all patients value the same treatment features equally and understanding of this variation has important implications for healthcare policy decisions. The results of this analysis could be used by stakeholders to guide decisions around the value of new 
myeloma medicines (eg, to establish more patient-aligned endpoints in clinical trials or as patient-focussed evidence which is incorporated into the Health Technology Assessment process to understand how patients value treatments).

\section{Key Points}

- Current treatments for multiple myeloma aim to increase overall survival, prolong remission and improve quality of life for patients, however they also incur variable risks of negative physiological effects, as well as potential financial and practical burdens on patients. Research suggests that healthcare professionals are often unaware of patients' preferences for treatment for myeloma and may underestimate patient quality of life.

- This study aimed to uncover how patients trade-off the benefits and risks/costs of myeloma treatment and to elicit their preferences on treatment attributes that are common to a broad range of myeloma treatments currently available.

- This evidence for myeloma patient preferences is critical for informing the future development and prioritisation of new treatments, and in assisting regulators and health technology assessment agencies to understand the acceptability and value proposition of new treatments.

\section{Ethical Approval}

The study was conducted in line with internal Myeloma UK ethical guidelines. All patients were provided with detailed study information in a participant information section of the survey and asked explicitly to consent to participate in the study. The study did not seek additional ethics approval because it was identified as a low risk non-intervention study.

\section{Acknowledgments}

The work in this manuscript was presented at the European Hematology Association (EHA) conference, Madrid, Spain; June 22-25, 2017 as a poster presentation. The authors would like to thank the patients with Myeloma who took part in the research for their time and contribution to this study.

\section{Author Contributions}

Simon Fifer contributed to the study design, data collection, data analysis, interpretation of results, writing and reporting. Jayne Galinsky and Sarah Richard contributed to the study design, data collection, interpretation of results, writing and reporting. All authors made substantial contributions to conception and design, acquisition of data, or analysis and interpretation of data; took part in drafting the article or revising it critically for important intellectual content; gave final approval of the version to be published; and agree to be accountable for all aspects of the work.

\section{Funding}

This study was partially supported by a grant from Bristol Myers Squibb (BMS) to Myeloma UK.

\section{Disclosure}

Jayne Galinsky and Sarah Richard were both employees of Myeloma UK. Simon Fifer is a Director of CaPPRe who were contracted by Myeloma UK to design the experiment, provide data management and conduct the analysis. Simon Fifer reports grants from Myeloma UK, during the conduct of the study; CaPPRe fees from Abbvie, Amgen, AstraZeneca, Celgene, GSK, Ipsen, Janssen, Roche, Sanofi, and Shire, outside the submitted work. The authors report no other conflicts of interest in this work.

\section{References}

1. Palumbo A, Anderson K. Multiple Myeloma. N Eng J Med. 2011;364 (11):1046-1060. doi:10.1056/NEJMra1011442

2. Cancer Research UK. Myeloma Statistics. 2013Available from: www. cancerresearchuk.org/health-professional/cancer-statistics/statisticsby-cancer-type/myeloma. Accessed July 4, 2020.

3. Osborne TR, Ramsenthaler C, Siegert RJ, et al. What issues matter most to people with multiple myeloma and how well are we measuring them? A systematic review of quality of life tools. Eur J Haematol. 2012;89(6):437-457. doi:10.1111/ejh.12012

4. Johnsen AT, Tholstrup D, Petersen MA, et al. Health related quality of life in a nationally representative sample of haematological patients. Eur $J$ Haematol. 2009;83(2):139-148. doi:10.1111/j.1600-0609.2009.01250.x

5. Muhlbacher AC, Nubling M. Analysis of physicians' perspectives versus patients' preferences: direct assessment and discrete choice experiments in the therapy of multiple myeloma. Eur J Health Econ. 2011;12(3):193-203.

6. Mantyselka P, Kumpusalo E, Ahonen R, et al. Pain as a reason to visit the doctor: a study in Finnish primary health care. Pain. 2001;89 (2-3):175-180. doi:10.1016/S0304-3959(00)00361-4

7. Suarez-Almazor ME, Conner-Spady B, Kendall CJ, et al. Lack of congruence in the ratings of patients' health status by patients and their physicians. Med Decis Making. 2001;21(2):113-121. doi:10.1177/02729890122062361

8. Bekker-Grob EW, Donkers B, Jonker MF, et al. Sample size requirements for discrete-choice experiments in healthcare: a practical guide. Patient Centered Outcomes Res. 2015;8(5):373-384. doi:10.1007/s40271-015-0118-z

9. Hensher DA, Rose JM, Greene WH. Applied Choice Analysis. Cambridge University Press; 2015.

10. Bridges JFP, Hauber AB, Marshall D, et al. Conjoint analysis applications in health - a checklist: a report of the ISPOR good research practices for conjoint analysis task force. Value Health. 2011;14 (4):403-413. doi:10.1016/j.jval.2010.11.013

11. Thurstone LL. A law of comparative judgment. Psychol Rev. 1927;4 (34):273-286. doi:10.1037/h0070288 
12. McFadden DL. Conditional Logit Analysis of Qualitative Choice Analysis, Ed. F.i. Econometrics. New York Academic Press; 1974.

13. Lancaster KJ. A New Approach to Consumer Theory. J Political Economy. 1966;74:132-157.

14. Hensher DA, Rose J. Choice Modelling: Foundational Contributions. Edward Elgar Publishing; 2011.

15. Louviere JJ, Woodworth G. Design and analysis of simulated consumer choice or allocation experiments: an approach based on aggregate data. J Marketing Res. 1983;20(4):350-367. doi:10.1177/ 002224378302000403

16. Louviere JJ, Hensher DA. On the design and analysis of simulated choice or allocation experiments in travel choice modelling. Transp Res Rec. 1982;890(1982):11-17.

17. Hess S, Daly A. Handbook of Choice Modelling. Edward Elgar Publishing; 2014.

18. Soekhai V, de Bekker-grob EW, Ellis AR, et al. Discrete choice experiments in health economics: past, present and future. Pharmacoeconomics. 2019;37(2):201-226. doi:10.1007/s40273-018-0734-2

19. Bauer S, Mueller S, Ratsch B, et al. Patient preferences regarding treatment options for relapsed refractory multiple myeloma (RRMM). Value Health. 2017;20(9):A451. doi:10.1016/j.jval.2017.08.299

20. Mühlbacher AC, Lincke H-J, Nübling M. Evaluating Patients' Preferences for Multiple Myeloma Therapy, a Discrete-ChoiceExperiment. Vol. 5. GMS Psycho-Social Medicine; 2008:Doc10.

21. Bolt T, Mahlich J, Nakamura Y, et al. Hematologists' preferences for first-line therapy characteristics for multiple myeloma in japan: attribute rating and discrete choice experiment. Clin Ther. 2018;40 (2):296-308.e2. doi:10.1016/j.clinthera.2017.12.012

22. Yong K, Delforge M, Driessen C, et al. Multiple myeloma: patient outcomes in real-world practice. Br J Haematol. 2016;175(2):252264. doi:10.1111/bjh.14213

23. Muhlbacher AC, Nübling M. Analysis of physicians' perspectives versus patients' preferences: direct assessment and discrete choice experiments in the therapy of multiple myeloma. Eur J Health Econ. 2011;3(89):175-180.

24. Mühlbacher AC, Nübling M. Analysis of physicians' perspectives versus patients' preferences: direct assessment and discrete choice experiments in the therapy of multiple myeloma. Eur $J$ Health Economics. 2011;12(3):193-203. doi:10.1007/s10198-010-0218-6

25. Reed Johnson F, Lancsar E, Marshall D, et al. Constructing experimental designs for discrete-choice experiments: report of the ISPOR conjoint analysis experimental design good research practices task force. Value Health. 2013;16(1):3-13. doi:10.1016/j.jval.2012.08.2223

26. ChoiceMetrics. Ngene, in User Manual \& Reference Guide. Australia: ChoiceMetrics; 2018.
27. Boeri M, Saure D, Schacht A, et al. Modeling Heterogeneity in Patients' Preferences for Psoriasis Treatments in a Multicountry Study: A Comparison Between Random-Parameters Logit and Latent Class Approaches. PharmacoEconomics. 2020.

28. Hensher DA, Rose JM, Greene WH. Applied Choice Analysis. Second ed. Cambridge: Cambridge University Press; 2015.

29. Greene WH. Nlogit. Econometric Software, Inc; 2019.

30. Zhou M, Thayer WM, Bridges JFP. Using latent class analysis to model preference heterogeneity in health: a systematic review. Pharmacoeconomics. 2018;36(2):175-187. doi:10.1007/s40273-0170575-4

31. Hauber ABP, González JM, Groothuis-Oudshoorn CGM, et al. Statistical methods for the analysis of discrete choice experiments: a report of the ISPOR conjoint analysis good research practices task force. Value Health. 2016;19(4):300-315. doi:10.1016/j.jval.2016.04.004

32. Gonzalez JM. A guide to measuring and interpreting attribute importance. Patient. 2019;12(3):287-295. doi:10.1007/s40271-019-00360-3

33. Fifer S, Rose J, Hamrosi KK, et al. Valuing injection frequency and other attributes of type 2 diabetes treatments in Australia: a discrete choice experiment. BMC Health Serv Res. 2018;18(1):675. doi:10.1186/s12913-018-3484-0

34. Team, R. RStudio: Integrated Development for R. Rstudio, Inc. RStudio Team; 2019.

35. Jansen SJ, Kievit J, Nooij MA, et al. Patients' preferences for adjuvant chemotherapy in early-stage breast cancer: is treatment worthwhile? $\mathrm{Br} \mathrm{J}$ Cancer. 2001;84(12):1577-1585. doi:10.1054/bjoc.2001.1836

36. Hamelinck VC, Bastiaannet E, Pieterse AH, et al. Patients' preferences for surgical and adjuvant systemic treatment in early breast cancer: a systematic review. Cancer Treat Rev. 2014;40(8):10051018. doi:10.1016/j.ctrv.2014.06.007

37. Wilke T, Mueller S, Bauer S, et al. Treatment of relapsed refractory multiple myeloma: which new PI-based combination treatments do patients prefer? Patient Prefer Adherence. 2018;12:2387-2396. doi:10.2147/PPA.S183187

38. Postmus D, Richard S, Bere N, et al. Individual trade offs between possible benefits and risks of cancer treatments: results from a stated preference study with patients with multiple myeloma. Oncologist. 2018;23(1):44-51. doi:10.1634/theoncologist.2017-0257

39. Osborne TR, Ramsenthaler C, Schey SA, et al. Improving the assessment of quality of life in the clinical care of myeloma patients: the development and validation of the myeloma patient outcome scale (MyPOS). BMC Cancer. 2015;15(1):280. doi:10.1186/s12885-015-1261-6

40. Molassiotis A, Wilson B, Blair S, et al. Unmet supportive care needs, psychological well-being and quality of life in patients living with multiple myeloma and their partners. Psycho-Oncology. 2011;20 (1):88-97. doi:10.1002/pon. 1710
Patient Preference and Adherence

\section{Publish your work in this journal}

Patient Preference and Adherence is an international, peer-reviewed, open access journal that focuses on the growing importance of patient preference and adherence throughout the therapeutic continuum. Patient satisfaction, acceptability, quality of life, compliance, persistence and their role in developing new therapeutic modalities and compounds to optimize clinical outcomes for existing disease states are major areas of interest for the journal. This journal has been accepted for indexing on PubMed Central. The manuscript management system is completely online and includes a very quick and fair peer-review system, which is all easy to use. Visit http:// www.dovepress.com/testimonials.php to read real quotes from published authors. 